Please do not remove this page

RMIT

UNIVERSITY

\title{
UV-induced wettability change of teflon-modified ZnO nanorod arrays on LiNbO3 substrate
}

Zheng, Hai; Breedon, Michael; Kalantar Zadeh, Kourosh

https://researchrepository.rmit.edu.au/esploro/outputs/9921863939601341/filesAndLinks?institution=61RMIT_INST\&index=null

Zheng, H., Breedon, M., \& Kalantar Zadeh, K. (2008). UV-induced wettability change of teflon-modified $\mathrm{ZnO}$ nanorod arrays on LiNbO3 substrate. Proceedings of the 2008 International Conference on Nanoscience and Nanotechnology, 218-221. https://doi.org/10.1109/ICONN.2008.4639286

Published Version: https://doi.org/10.1109/ICONN.2008.4639286

Repository homepage: https://researchrepository.rmit.edu.au

(c) 2008 IEEE. Personal use of this material is permitted. However, permission to reprint/republish this material for advertising or promotional purposes or for creating new collective works for resale or redistribution to servers or lists, or to reuse any copyrighted component of this work in other works must be obtained from the IEEE.

Downloaded On 2023/04/26 18:38:58 +1000 


\title{
UV-induced Wettability Change of Teflon-modified $\mathrm{ZnO}$ Nanorod Arrays on $\mathrm{LiNbO}_{3}$ Substrate
}

\author{
Haidong Zheng, Michael Breedon, Kourosh Kalantar-zadeh \\ Sensor Technology Laboratory, School of Electrical and Computer Engineering, RMIT University, Melbourne, \\ AUSTRALIA \\ Email: s3027827@student.rmit.edu.au
}

\begin{abstract}
Aligned $\mathrm{ZnO}$ nanorod arrays films were grown on $\mathrm{LiNbO}_{3}$ substrates by aqueous growth, and subsequently rendered superhydrophobic with $\mathrm{RF}$ sputtered coated Teflon. The as-prepared surface exhibits superhydrophobicity with a water contact angle (CA) of $154.5^{\circ}$. After 2 hours of UV irradiation on the surface, the surface wettability was approaching hydrophilic state; CA was measured to be $113^{\circ}$. This study provides insights into the methodology of a low cost, efficient technique that has great potential for preparing nanostructured surface with tunable wettability [1].
\end{abstract}

Keywords-ZnO; nanorod; superhydrophobicity; wettability; $U V$ irradiation

\section{Introduction}

Wettability is one of the most important properties of solid surfaces, which is mostly governed by the surface free energy as well as the geometric structure of the surface [2]. Tunable wettability has a wide range of applications; examples citied in literature include, fluid microchips and micro-reactors, it is crucial to have the ability to prepare surfaces with high contrast of wettability for water on the same kind of substrates [3]. Superhydrophobic surfaces are usually developed with a combination of a rough surfaces coupled with low surface energies, on which the latter is commonly achieved by coating materials with fluoroalkanesilane [2]. Feng et al in 2004 reported a reversible transition from superhydrophobicity to superhydrophilicity on aligned $\mathrm{ZnO}$ nanorod films induced by UV light [5]. Following this achievement, other nanostructured metal oxides with tunable wettability induced upon irridation of UV light were studied [6-8]. However, the $\mathrm{UV}$-induced decline of hydrophobicity on Teflon-modified $\mathrm{ZnO}$ nanostructured surface has not been reported.

\section{Experiments and Discussion}

For the preparation of $\mathrm{ZnO}$ nanorod growth, the $\mathrm{LiNbO}_{3}$ substrate was RF sputter coated with a $1.2 \mu \mathrm{m} \mathrm{ZnO}$ seed layer as seen in Figure 1. Such a seed layer improves the uniformity and orientation of $\mathrm{ZnO}$ nanostructured arrays and facilitates their growth. Nanostructured arrays of $\mathrm{ZnO}$ were grown in a sealed reaction vessel via the hydrothermal decomposition of $10 \mathrm{mM}$ of HMT / zinc nitrate hexahydrate $\left(\mathrm{Zn}\left(\mathrm{NO}_{3}\right)_{2} \cdot 6 \mathrm{H}_{2} \mathrm{O}\right)$ solutions as described by L. Vayssieres [9]. In this process, reaction vessel was placed inside an oven for $20 \mathrm{hrs}$ at $80^{\circ} \mathrm{C}$. After which the substrates were extricated and washed with DI water to remove any residual zinc salts and dried in a stream of $\mathrm{N}_{2}$.
The $\mathrm{ZnO}$ nanostructure coverage and morphology was observed by FEI Nova nanoSEM. ZnO nanorods grown on $\mathrm{LiNbO}_{3}$ substrates exhibit uniform growth that occurs at a high density as seen in Figure 2. $\mathrm{LiNbO}_{3}$ substrate bound nanorods have a large variation in width ranging between approx $125 \mathrm{~nm}$ to $200 \mathrm{~nm}$ as can be seen in Figure 3. This width variation plays an important role in roughing the surface.
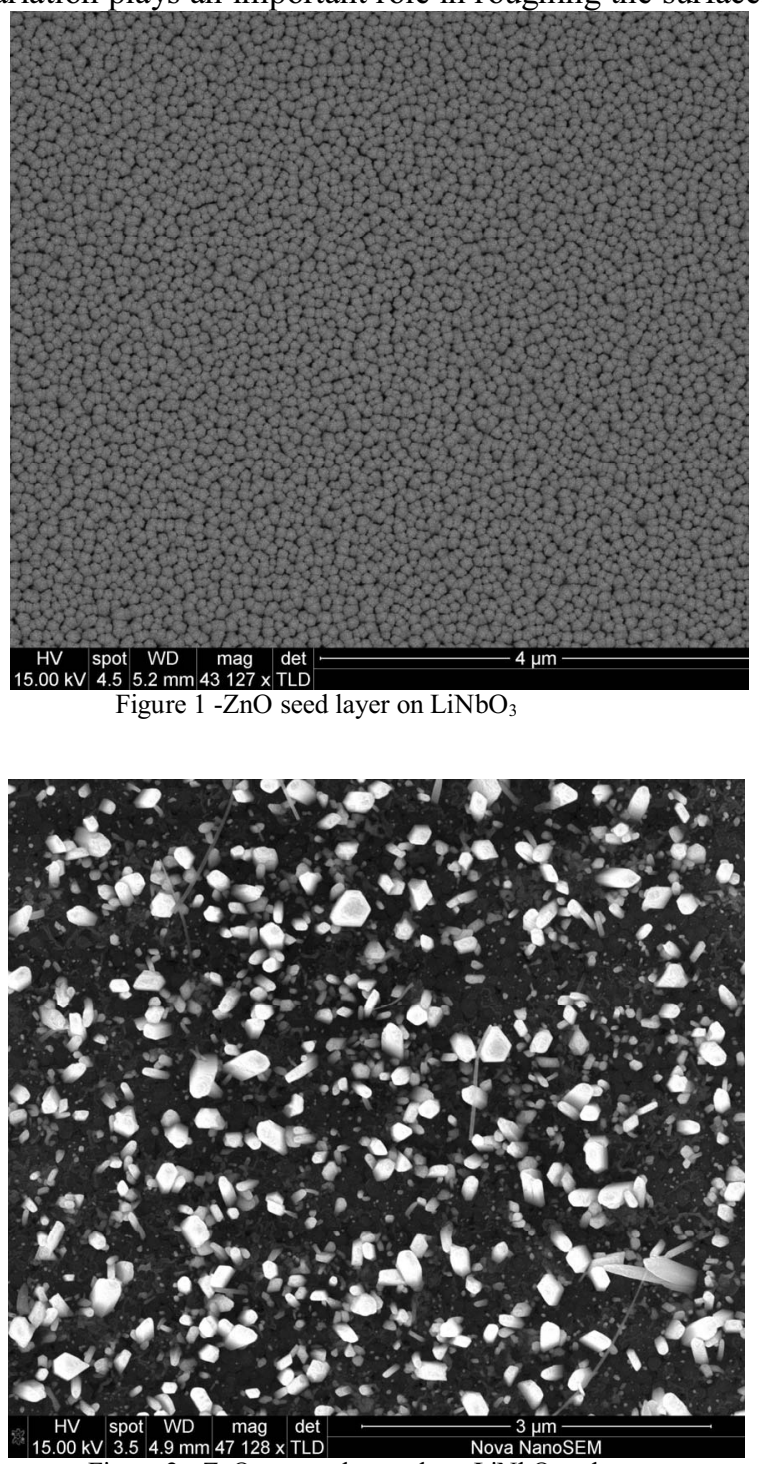

Figure 2 - $\mathrm{ZnO}$ nanorod growth on $\mathrm{LiNbO}_{3}$ substrate 


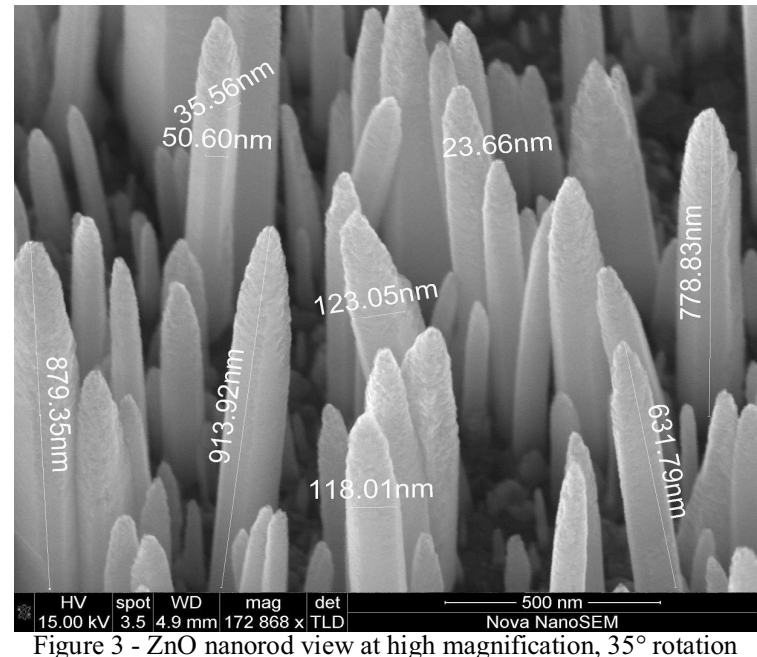

Figure 3 - $\mathrm{ZnO}$ nanorod view at high magnification, $35^{\circ}$ rotation

A water droplet was placed onto the prepared surface, it was observed that the droplet quickly spreads away, and leaving a water contact angle less than $5^{\circ}$ (Figure 4). This strongly indicates that $\mathrm{ZnO}$ nanorod arrays exhibits superhydrophilicity. According to Wenzel's model which hypothesizes that the liquid completely penetrates into the troughs of the surface texture, surface roughness enhances not only hydrophobic but also hydrophilic properties [11]. That is on a flat homogenous surface, if the contact angle is less than $90^{\circ}$, roughness will make the surface even more hydrophilic; if greater than $90^{\circ}$, roughness will enhance the hydrophobicity [13]. In this case, the CA on flat surface of $\mathrm{ZnO}$ single crystal is only $31^{\circ}$ (much smaller than $90^{\circ}$ ) [10], the surface roughness provided by the aligned $\mathrm{ZnO}$ nanorod structure reduces the $\mathrm{CA}$ further, and introduces superhydrophilicity on the surface.

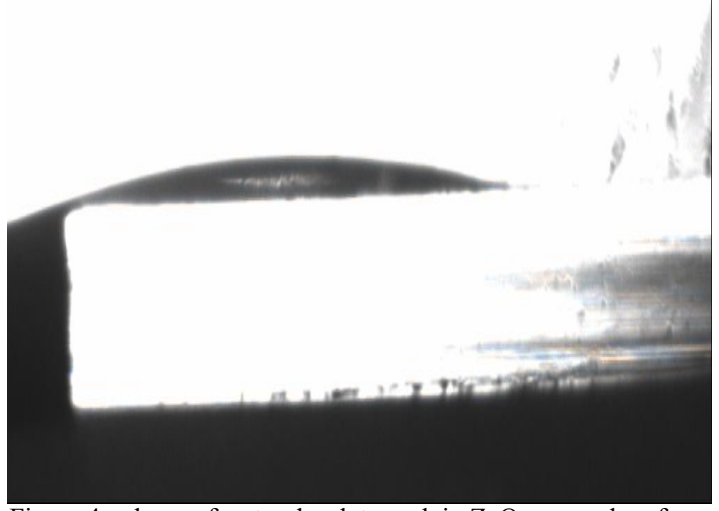

Figure 4 - shape of water droplet on plain $\mathrm{ZnO}$ nanorod surface.

In order to render the surface hydrophobic Teflon was used, as it is a well-known water repelling material due to its very low surface free energy [3]. The $\mathrm{ZnO}$ nanorod arrays are $\mathrm{RF}$ sputtered with a Teflon target, at $80 \mathrm{~W}$ for 20 minutes. This produces a $50-80 \mathrm{~nm}$ thick of Teflon layer on top of the $\mathrm{ZnO}$ nanorod arrays. As shown in Figure 5 and 6, the original $\mathrm{ZnO}$ morphology is well covered by Teflon.

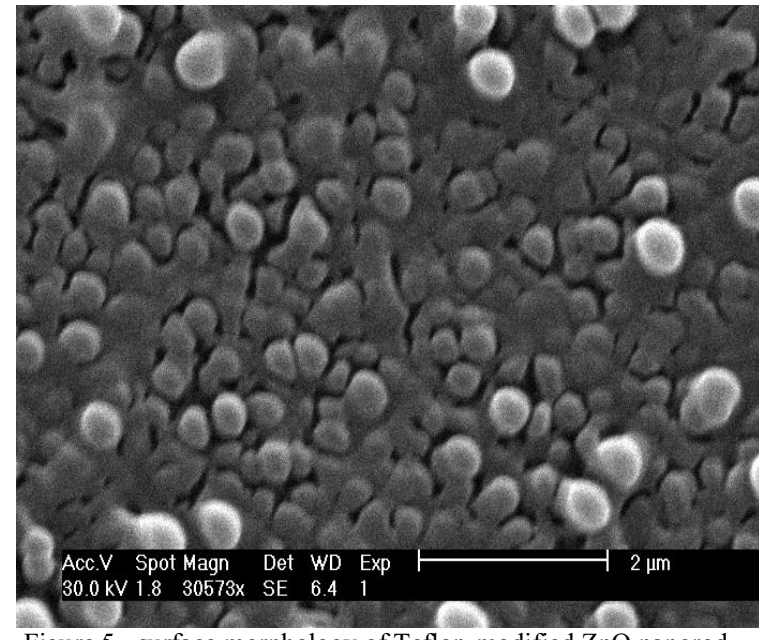

Figure 5 - surface morphology of Teflon-modified $\mathrm{ZnO}$ nanorod arrays

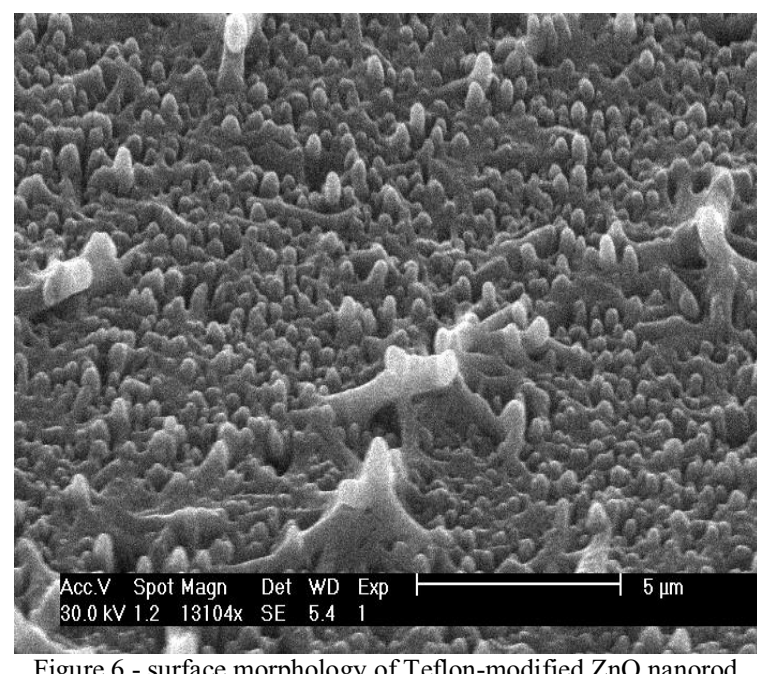

Figure 6 - surface morphology of Teflon-modified $\mathrm{ZnO}$ nanorod arrays, $15^{\circ}$ rotation

On a plain $\mathrm{ZnO}$ seed layer that is coated with Teflon, water contact angles were measured to be $110^{\circ}$ as seen in Figure 7, but $154.5^{\circ}$ on Teflon coated $\mathrm{ZnO}$ nanorod surface as seen in Figure 8 .

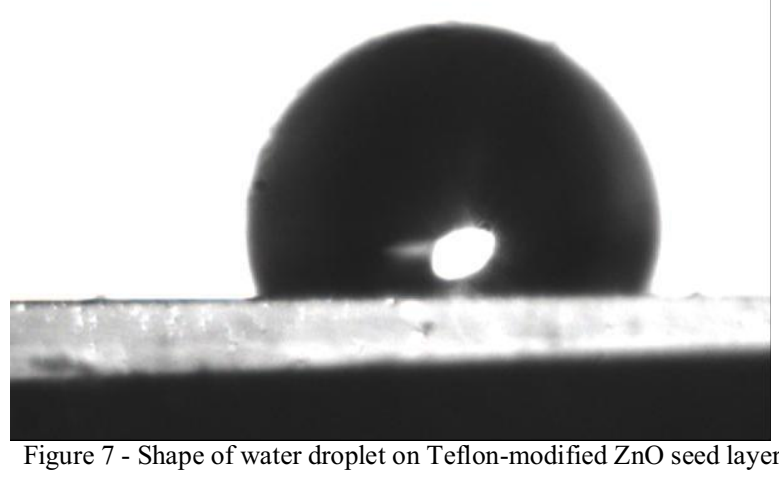




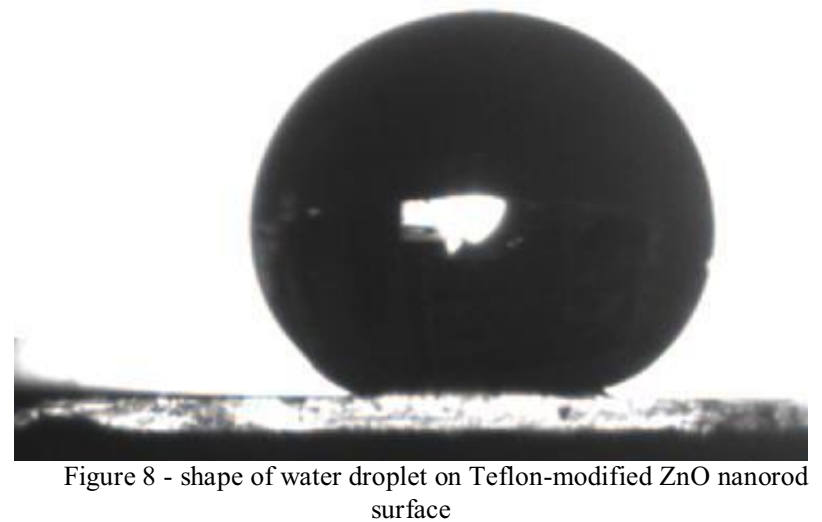

The difference in these two contact angles is ascribed to the difference of the roughness ratios on the respective surfaces. For a flat smooth and chemically homogeneous solid surface, the CA of a liquid droplet is defined by Young's equation

[11]:

$$
\operatorname{Cos} \theta=\frac{\sigma_{s v}-\sigma_{s l}}{\sigma_{l v}}
$$

where $\theta$ is the CA and $\sigma$ is the surface free energy. The indices represent the different interfaces: solid-vapor (sv), solid-liquid $(s l)$, and liquid-vapor $(l v)$. The wetting properties of the nanostructures, nevertheless, are different from the smooth films, which are described by Eqn. 1. In CassieBaxter's model which assumes the water droplet sits on top of the composite structure [12], the Young's equation is modified as:

$$
\operatorname{Cos} \theta_{w}=\gamma \frac{\sigma_{s v}-\sigma_{s l}}{\sigma_{l v}}
$$

where $\theta_{w}$ is the CA predicted by Cassie-Baxter's theory, and a roughness factor $\gamma$ is the ratio of the actual and the projected areas. With respect to the plain $\mathrm{RF}$ sputtered $\mathrm{ZnO}$ (shown in Fig. 7), the roughness factor is slightly bigger than 1 which is the roughness of a perfectly smooth $\mathrm{ZnO}$ surface. Conversely, the roughness factor of surface such as the $\mathrm{ZnO}$ nanorods (shown in Fig. 8), has an $r$ which is much larger than one. Thus, the increase in surface roughness due to the nanostructure results in a significantly larger CA compared to one on the smoother surface.

After UV irradiation for 2 hours, the CA of the water droplet on the Teflon-modified $\mathrm{ZnO}$ nanorod arrays decreased, and it was measured to be around $113^{\circ}$. Reversibility was slow as after 7 days of storing the sample in a dark environment, a CA was re-measured to be approximately $154^{\circ}$.

As illustrated in Figure 10, even though the Teflon layer is not conformal on top of the $\mathrm{ZnO}$ nanorods, together with the nanostructure, its surface energy is low enough to stop water droplet from filling up the gaps. But UV irradiation generates electron-hole pairs in the $\mathrm{ZnO}$ nanorod, with some of the holes reacting with lattice oxygen to form surface oxygen vacancies. Later, water and oxygen may compete to adsorb on them on the areas which are not covered by Teflon. However, the defective sites are kinetically more favorable for hydroxyl adsorption than oxygen from air. As a result, the surface hydrophilicity is improved [5].
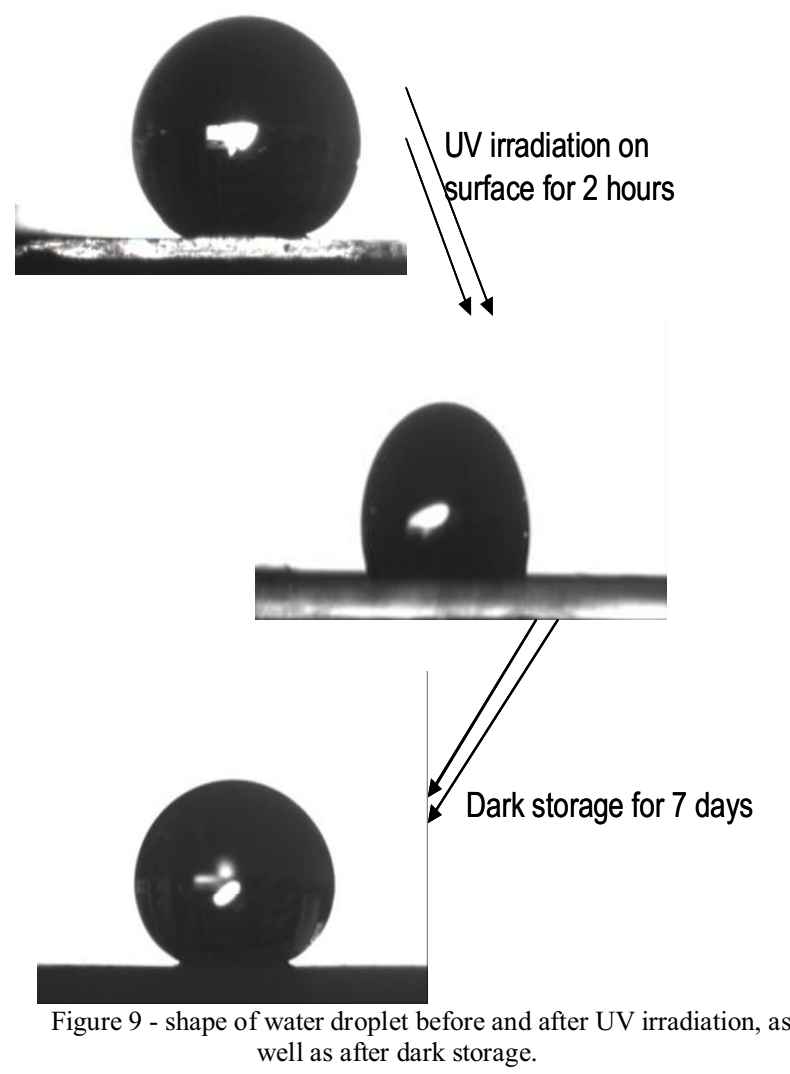


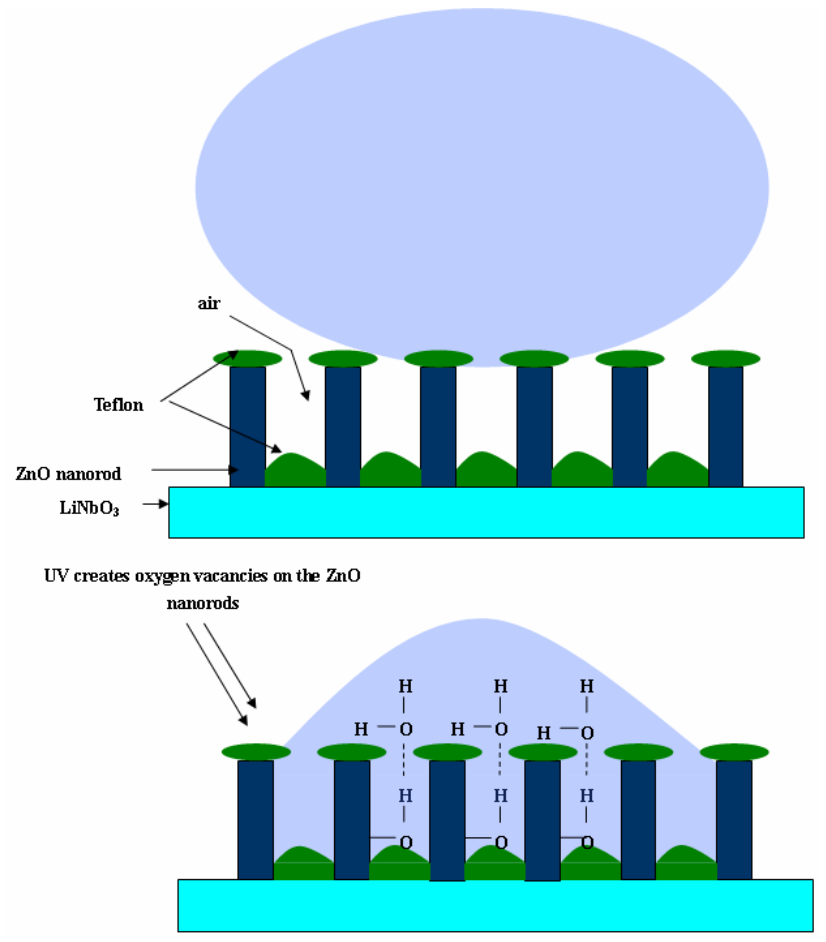

Figure 10 - mechanism of wettability change on Teflon coated $\mathrm{ZnO}$ nanorod surface
[5] Feng, X., L. Feng, et al. (2004). "Reversible Super-hydrophobicity to Super-hydrophilicity Transition of Aligned ZnO Nanorod Films." J. Am. Chem. Soc. 126(1): 62-63.

[6] Lim, H. S., D. Kwak, et al. (2007). "UV-Driven Reversible Switching of a Roselike Vanadium Oxide Film between Superhydrophobicity and Superhydrophilicity." J. Am. Chem. Soc. 129(14): 4128-4129.

[7] Xinjian Feng, J. Z. L. J. (2005). "The Fabrication and Switchable Superhydrophobicity of TiO Nanorod Films." Angewandte Chemie International Edition 44(32): 5115-5118.

[8] Zhang, X., M. Jin, et al. (2006). "Preparation and Photocatalytic Wettability Conversion of TiO-Based Superhydrophobic Surfaces." Langmuir 22(23): 9477-9479.

[9] Vayssieres, L. (2003). "Growth of Arrayed Nanorods and Nanowires of $\mathrm{ZnO}$ from Aqueous Solutions." Advanced Materials 15(5): 464-466

[10] Doshi, D. A., P. B. Shah, et al. (2005). "Investigating the Interface of Superhydrophobic Surfaces in Contact with Water." Langmuir 21(17): $7805-7811$.

[11] R.N. Wenzel, Ind. Eng. Chem. 28 (1936) 988.

[12] Cassie, A. B. D.; Baxter, S. Trans. Faraday Soc. 1944, 40, 546.

[13] N.S. Pesika, Z. Hu, K.J. Stebe, P.C. Searson, J. Phys. Chem., B 106 (2002) 6985.
III. Conclusion and Future Development

In summary, a highly oriented single-crystalline $\mathrm{ZnO}$ nanorod arrays has been prepared by an aqueous hydrothermal method, such surfaces are then RF sputtered with Teflon to obtain superhydrophobicity. This fabrication is simple, low cost, and efficient. Additionally, it has been experimentally demonstrated that, the wettability on Teflon-modified $\mathrm{ZnO}$ nanorod arrays is a function of UV irradiation.

Further research is underway to improve the response time of wettability change by using a combination of UV light and electric potential. Also the recovery times can be shortened by placing the sample in an oxygen rich environment at high temperature. Furthermore, better photo-sensitive materials such as $\mathrm{TiO}_{2}$ and $\mathrm{WO}_{3}$ are being studied to complement this study.

\section{REFERENCES}

[1] Campbell, J.L.,Breedon, M.,Latham, K., Kalantar-zadeh, K, "Electrowetting of Superhydrophobic ZnO Nanorods". 2008, Langmuir (in press)

[2] Garbassi, F.M., Marco. Occhiello, E., Polymer surfaces : from physics to technology, Rev. and updated ed ed. 1998, New York, Wiley.

[3] Gras SL, Mahmud T, Rosengarten G, Mitchell A, Kalantar-Zadeh K. "Intelligent control of surface" hydrophobicity Chemphyschem. 2007 ;8(14):2036-50

[4] Guo, M., P. Diao, et al. (2007). "Highly hydrophilic and superhydrophobic ZnO nanorod array films." Thin Solid Films 515(18): 7162-7166. 